\title{
Histopathologic Profile of Miscarriages during First Trimester of Pregnancy in Teaching Hospital of Grand Yoff in Dakar (Senegal)
}

\author{
Mama Sy Diallo ${ }^{*}$, Chérif Mohamed Dial' ${ }^{2}$, Henriette Poaty ${ }^{3,4}$, Oumar Faye ${ }^{1}$ \\ ${ }^{1}$ Histology-Embryology and Cytogenetics Laboratory, Faculty of Medicine, Cheikh Anta Diop University, Dakar, Senegal \\ ${ }^{2}$ Service of Pathology, Teaching Universitary Hospital of Grand Yoff, Dakar, Senegal \\ ${ }^{3}$ Histology-Embryology and Genetics Unit, Faculty of Health Sciences of Brazzaville, Brazzaville, Congo \\ ${ }^{4}$ National Research Institute on Health Sciences, Brazzaville, Congo \\ Email:^mamatasy@yahoo.fr
}

How to cite this paper: Diallo, M.S., Dial, C.M., Poaty, H. and Faye, O. (2020) Histopathologic Profile of Miscarriages during First Trimester of Pregnancy in Teaching Hospital of Grand Yoff in Dakar (Senegal). Open Journal of Pathology, 10, 56-65.

https://doi.org/10.4236/ojpathology.2020.101 006

Received: December 13, 2019

Accepted: January 12, 2020

Published: January 15, 2020

Copyright (c) 2020 by author(s) and Scientific Research Publishing Inc. This work is licensed under the Creative Commons Attribution International License (CC BY 4.0).

http://creativecommons.org/licenses/by/4.0/

Open Access

\begin{abstract}
Background: Mainly for economic reasons, histopathologic analysis is not a systematic practice in medical structures in Senegal, and the utility of this exam is being questioned by many authors. The purpose of this paper is to report the results of this exam, in our medical practice and try to determine if this exam should be systematic of kept only for individualized cases. Material and Methods: It was a retrospective study from January 2010 to December 2018, carried out in the Laboratory of Pathology of the Teaching Hospital of Grand Yoff in Dakar. The data were collected from the register of pathologic examinations of the laboratory. Results: We registered 543 results of histopathologic examination of products of conception from the first trimester abortion. The women mean age was 22.4 years \pm 6.2 with extremes of 17 and 46 years. The routine histopathologic assessment of products of firsttrimester miscarriages highlighted in our study three pathologies: hydatidiform mole (24.7\%), infection (4.6\%) and ectopic pregnancy (0.09\%). Only $11.7 \%$ of cases of Hydatidiform mole (HM) were suspected before the histopathologic assessment. In our sample, molar pregnancy seems to be higher in anembryonic conception with a prevalence of $45 \%$. The prevalence of Complete Hydatidiform Mole (CHM) was higher than the one of Partial Hydatidiform Mole (PHM) (14.8\% vs. 9.9\% of miscarriages). Indeed, both require follow up to prevent or manage at time the occurrence of choriocarcinoma. Conclusion: The results of the histologic analysis after abortion in the first trimester of pregnancy show that this exam should be practiced systematically in routine in our context because of high prevalence of hydatidiform mole.
\end{abstract}




\section{Keywords}

Histopathologic, Miscarriage, Hydatidiform Mole, Ectopic Pregnancy

\section{Introduction}

For economic reasons, systematic histological assessment of tissue from uterine evacuation was recently questioned [1]. Histopathologic assessment after miscarriage during the first trimester of pregnancy remains a recommendation for many reasons, especially for the diagnosis of Gestational trophoblastic disease (GTD). As being part of developing countries, the prevalence of Hydatidiform mole (HM) in Senegal is estimated to be 2 to 10 times higher than in the western countries [2] [3]. The incidence of hydatidiform mole in Senegal is 1/400 pregnancies [4]. This statement was associated with poor nutritional factors like the deficit in carotene [4] [5]. Hydatidiform moles (HM) are genetically abnormal conceptions characterized by hydropic chorionic villi, trophoblastic hyperplasia, poor development and an increased risk of progressing to malignant disease [6]. Classically, partial hydatidiform mole (PHM) is considered as the non-invasive form of the gestational trophoblastic diseases [7] but the recent reports about sporadic cases of PHM degenerating in choriocarcinoma questioned the management of this entity [8]. The study of Seckl [9], was the first to demonstrate the potential of malignant transformation of PHM, so the follow-up of partial mole is warranted as in complete hydatidiform mole (CHM). In Aristide Le Dantec University Hospital in Dakar, one HM conception is registered for every eight misconceptions with up to $30 \%$ of CHM degenerating into choriocarcinoma [10]. According to Seckl and Sebire [9] [11], the usual management of abortions is not enough to detect all molar pregnancies because tissue is not routinely submitted for histological examination especially in resource-limited regions.

The aim of our study was to report the results of the histologic analysis after spontaneous and chirurgical abortions in the first trimester of pregnancy, insisting on the profile of molar pregnancies. We also propose recommendations concerning the management of miscarriages in our practice in Senegal.

\section{Material and Methods}

\subsection{Material}

It was a retrospective study from January 2008 to December 2018, carried out in the Laboratory of Pathology in the Teaching Hospital of Grand Yoff in Dakar. The material was the register of pathologic examinations in the laboratory.

We collected the results of the histological exam from conception products received for assessment after an abortion during the first trimester of pregnancy (5 to 14 weeks of gestation). 


\subsection{Methods}

We collected data concerning the age of the patients, and the results of the histological examination (microscopy). We excluded in the study the samples without histological results diagnosis. Slides were analyzed using the hematoxylin and eosin (HE) protocol: fixation of tissues in $10 \%$ formaldehyde, embedding in paraffin blocks and sections of 5 microns were taken; The slides were stained with HE. Complete hydatidiform mole (CHM) was diagnosed by the visualization of one population of hydropic villi with trophoblastic hyperplasia while Partial hydatidiform mole (PHM) was diagnosed histopathologically when the four following microscopic features coexisted: 1) two populations of villi; 2) enlarged villi (> or $=3-4 \mathrm{~mm}$ ) with central cavitation; 3 ) irregular villi with geographic; scalloped borders with trophoblast inclusions; and 4) trophoblast hyperplasia (usually focal and involving syncytiotrophoblast).

\section{Results}

We collected 543 results of histopathologic examination of products of conception from the first trimester abortion. The women mean age was 22.4 years \pm 6.2 with extremes of 17 and 46 years. The sample was mostly obtained after uterine evacuation, but five samples were collected after a surgery. The histopathology confirmed the diagnosis of abortion with presence of chorionic villi, trophoblast, the presence of fetal tissue, and gestational endometrium with decidual tissue. The specimens were predominantly hydatidiform mole followed by infections and ectopic pregnancy.

\section{Infection}

The infectious inflammation of the endometrium or the trophoblast was noted in $4.6 \%$ cases, with infiltration of leucocytes, lymphocytes and macrophages, realizing an endometritis or a chorioamnionitis. Two cases presented stigmatism of chronic salpingitis with microscopically the presence of inflammatory cells with lymphocytes in the mucosa with some plical distortions.

\section{Ectopic pregnancy}

Ectopic pregnancies located only in the fallopian tubes (Figure 1(a), Figure 1(b)) were observed in five cases (i.e. 0.09\%). Microscopic examination allowed to visualize chorionic villi (Figure 1(c), Figure $1(\mathrm{~d})$ ) in the tube confirming the tubal pregnancy. Two samples presented associated chronic salpingitis.

\section{Hydatidiform mole (HM)}

The global prevalence of HM was $24.7 \%$ of miscarriages. The histopathologic analysis confirmed CHM in 14.8\% (80 cases) and PHM in 9.9\% (54 cases), (Figure 2). Some microscopic aspects of molar pregnancies in our sample are illustrated in Figure 2.

In most cases (89\%), the diagnosis of molar pregnancy was made exclusively by the microscopic examination and was not suspected clinically neither after the ultrasound exam (Figure 3). Retrospectively, the clinical suspicion of molar pregnancy was rare and PHM was only evocated in $1.5 \%$ of cases prior the evacuation $(\mathrm{n}=2)$. 

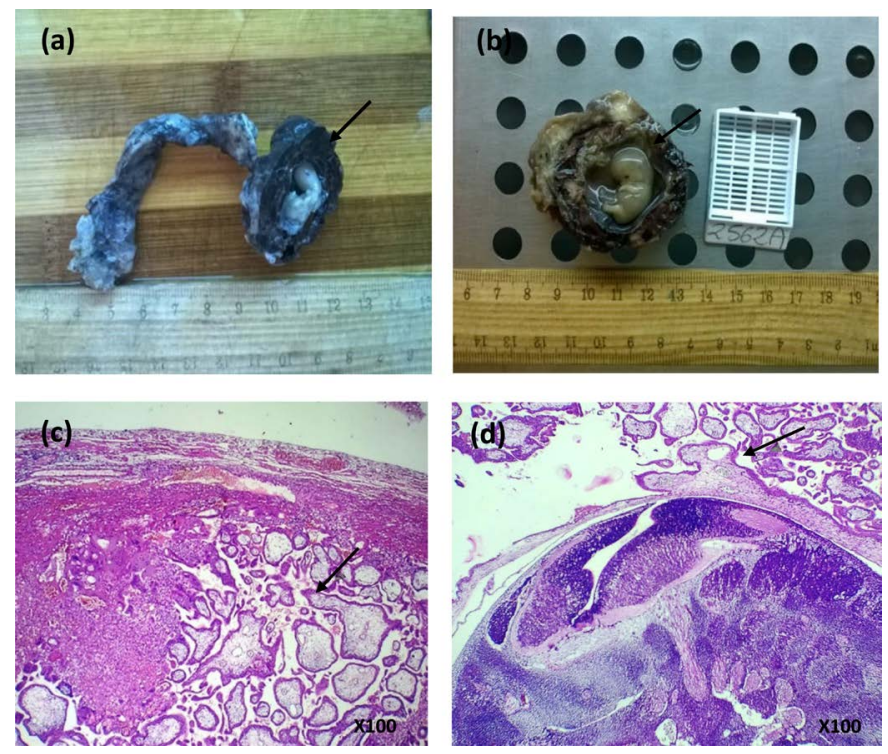

Figure 1. Anatomopathological aspects of ectopic pregnancy. Macroscopic aspects [(a) and (b)]: fallopian tube with presence of an embryo. Microscopic aspects [HE, (c) and (d)]: chorionic villi invading the tubal wall.
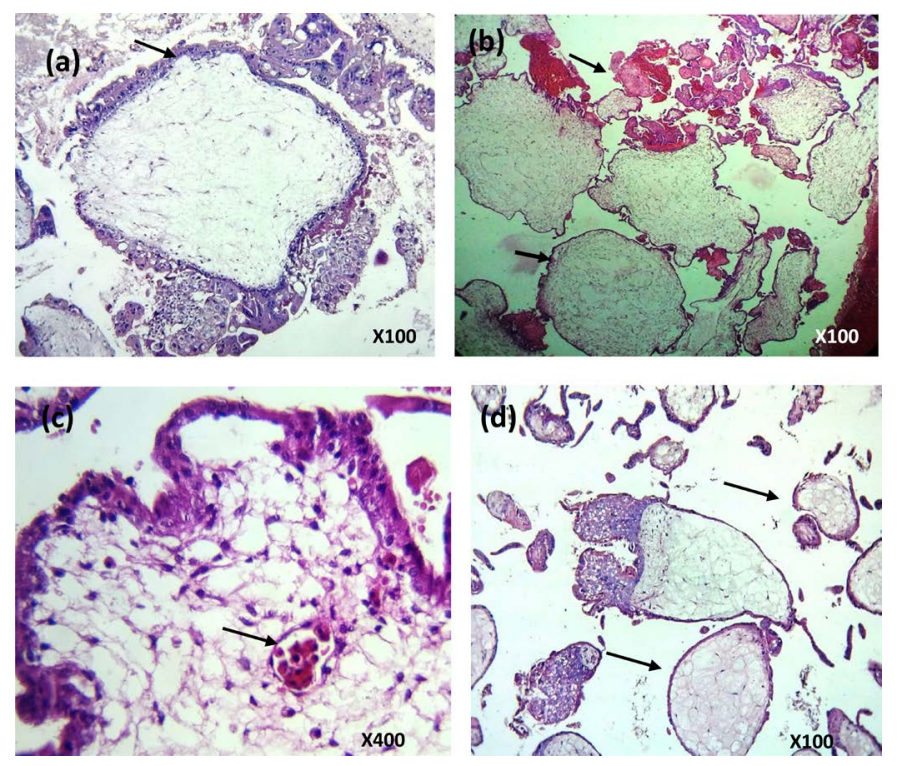

Figure 2. Microscopic aspects of molar pregnancies (HE). CHM (a): enlarged villi with round shape and circumferential cytotrophoblastic proliferation. PHM (b): two populations of chorionic villi; (c) nucleated Red blood cells (fetal cells) in blood vessels; (d) mixture of small and large irregular villi.

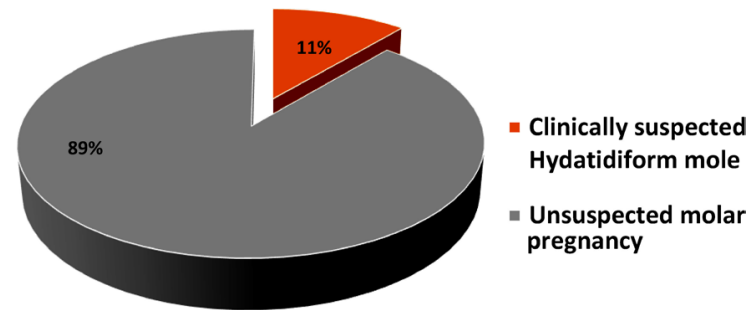

Figure 3. Assessment of molar pregnancy before histology. 
In anembryonic conceptions with blighted ovum $(\mathrm{n}=40)$, we noted a different prevalence of molar pregnancies that was $45 \%$ (28/40) with 28 molar pregnancies divided into $8 \mathrm{CHM}$ and $20 \mathrm{PMH}$. In this entity, the prevalence of molar pregnancy was higher than the one in the whole sample.

\section{Discussion}

The etiologies of miscarriages are often unknown. However, it is reported that chromosomal anomalies affect $2 \%-8 \%$ of couples with recurrent pregnancy loss [12]. In the present study, routine histopathologic assessment of products of first-trimester miscarriages highlights three pathologies: infection, ectopic pregnancy and hydatidiform mole.

\section{1) Infections}

Some tissues presented stigmatisms of infection with a prevalence of $4.6 \%$. The prevalence of infection was under the proportion reported by Musliya study [13] in Congo, which was $9.9 \%$ with the presence of severe decidual inflammation. Some authors as Ravindra [14] report that inflammation is a risk factor for ectopic pregnancy, especially in the fallopian tubes. Skibsted [15] also noted that women with salpingitis isthmica nodosa had a greater risk of tubal pregnancies.

\section{2) Hydatidiform mole}

HM is an entity of Gestational trophoblastic diseases (GTD) that consist of a group of neoplastic disorders arising from placental trophoblastic tissue after normal or abnormal fertilization [11]. The WHO classification of GTD includes hydatidiform mole, invasive mole, choriocarcinoma, placental site trophoblastic tumor, and miscellaneous and unclassified trophoblastic lesions [16]. In our sample, only hydatidiform mole was diagnosed. The global prevalence of molar pregnancy is almost 1 for 4 abortions (24.7\%).

This prevalence is higher than the frequency reported in previous studies in Dakar that was 1 for 8 miscarriages [10]. Among the risk factor indexed in the occurrence of HM in Senegal are nutritional factor and genetic predisposition [4] [5] [17].

Indeed, the study of samples in the same center in Dakar with choriocarcinomas revealed a mutation for NPL7 [3].

According to some reviews, the incidence of PHM is higher (1:695) compared to CHM (1:1945) [18]. The reported part of partial or complete mole are very variable through the world and it seems that in Asia and Middle East the tendency is represented by higher prevalence of complete mole [19]. According to Jeffers [18], PHM is an underdiagnosed condition because only (3.5\%) are suspected clinically. In our study, only $1.5 \%$ of PHM were suspected. Since Seckl study [9] that showed malignant transformation of PHM into choriocarcinoma [9], the follow up is warranted for both forms. In Sebire Study [11], thanks to ultrasonographic examination $58 \%$ of complete moles and $17 \%$ of partial moles had a correct pre-evacuation diagnosis of GTD. The diagnosis was clinically assessed in our study in only $11.5 \%$ of cases. 


\section{Risk of malignancy}

The major interest of histological analysis in HM is the early detection of malignant degeneration. Indeed, the risk of neoplasia is $15 \%$ after a CHM and $0.5 \%$ after a PHM [11]. In developing countries, up to 30\% of CHM degenerate into choriocarcinomas [20] [21] and so is the case in Senegal [10]. In Dakar, $66.6 \%$ of the histology of developed choriocarcinomas was not available after abortion [22].

\section{Genetic analysis}

In Poaty study [23], concerning cytogenetics of choriocarcinoma with samples of Aristide Le Dantec University Hospital of Dakar, all cases were histopathologically diagnosed as CHM except for one case that was diagnosed as PHM and had a triploid diandric genome. There is a distinction between PHM and CHM on the point of view of cytogenetics and embryology. PHM are triploid although $\mathrm{CHM}$ is the result of a diploid conception. Unusual variants are reported including co-existence of $\mathrm{HM}$ with normal twin and mosaic conception and a partly molar placenta; the different schemes of fertilization in molar pregnancy are sum up in Figure 4. Most of the tumors were andromonospermic but diploid spermatozoa can also be responsible for molar pregnancy [24]. This scheme has been described after Assisted Reproductive Technology after ICSI (Intra cytoplasmic injection of spermatozoa) with a normal oocyte and a diploid spermatozoon. A PHM occurred, confirming that possibility [25].

In Senegal population, the study of Slim showed that maternal NPRL7 mutation (located in 19q13.4 band) lead to HM with increased risk of choriocarcinoma [23]. In Tunisia, where GTD is frequent, NPRL7 gene is also identified in developed choriocarcinomas [3]. Lots of candidate genes are implicated [24] in apparition of choriocarcinoma with probably polygenic interactions. Determining a molecular biomarker for evolutivity of molar pregnancy towards choriocarcinoma is still a subject of research.

\section{Difficulty of the diagnosis}

Paradinas [26] showed in his study that a second analysis of slides with diagnosis of partial mole decreased the prevalence from $16 \%$ to $10 \%$. In early pregnancy, the histologic distinction between complete hydatidiform mole and nonmolar products of conception can be very difficult [27] justifying the use of immunochemistry. P57 is the gene product of the paternally imprinted, maternally expressed gene $C D K N 1 C$, a cyclin-dependent kinase inhibitor gene located on chromosome 11p15.5. It is expressed preferentially off the maternal allele and is therefore not expressed in complete hydatidiform molar villous stroma. So, p57KIP2 immunostaining appears to be a practical and accurate adjunct for the diagnosis of CHM [28] [29]. Nevertheless, highly reliable histopathological diagnostic features have now been described to allow accurate identification and subtyping of HM from early pregnancy products of conception [11].

In view of our study's findings, we recommend routine histopathological analysis of all products of conception especially anembryonic conceptions that presented higher prevalence of hydatidiform mole in ours samples. This statement must be assessed by further study with a larger cohort. 


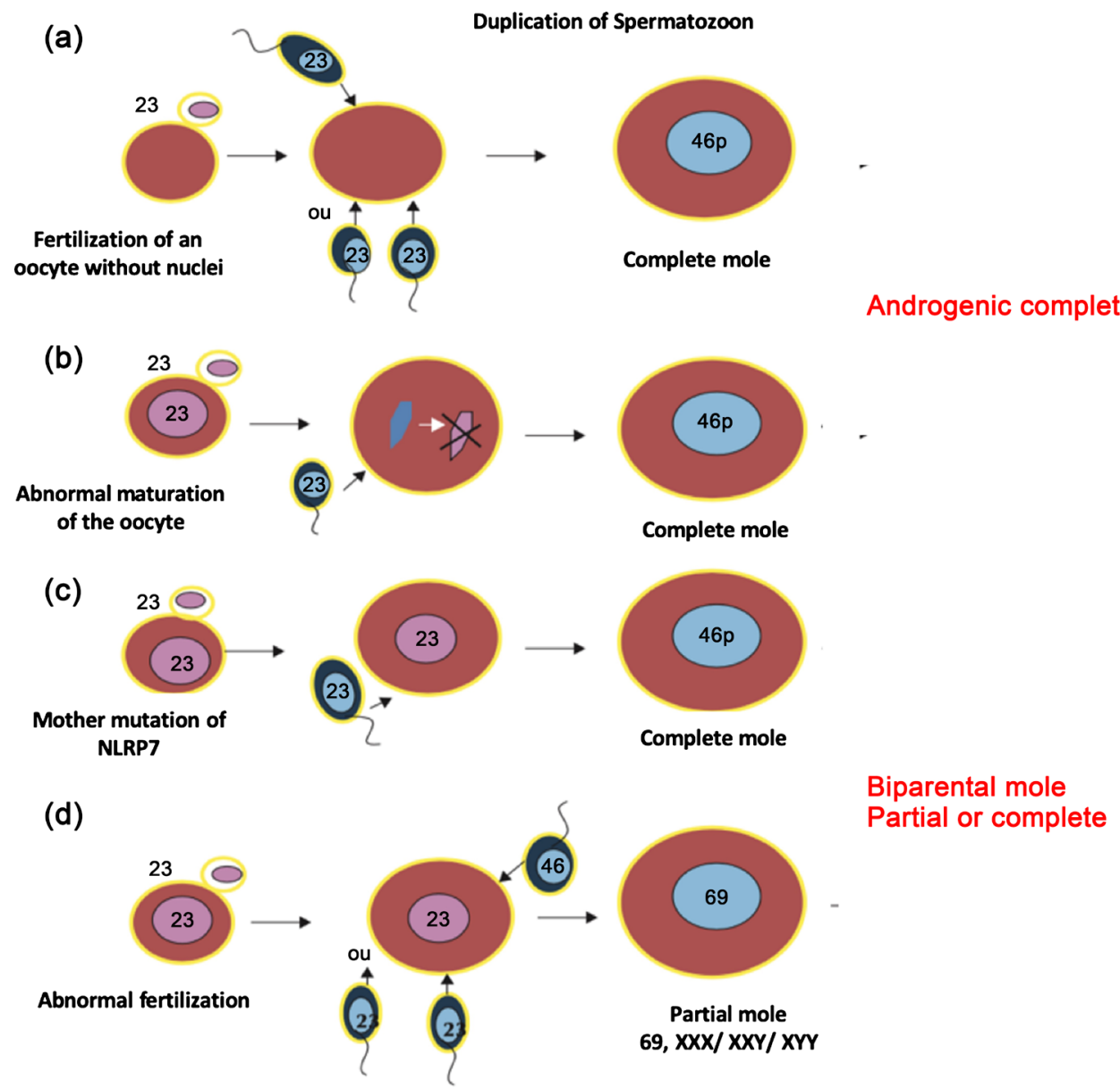

Figure 4. Different schemes of fertilization in hydatiform mole (according to Poaty et al.) [23]. (a) A CHM homozygous (fertilization of oocyte by a haploid spermatozoon and duplication of the genome) or a CHM heterozygous (fertilization of oocyte by two haploid spermatozoa). (b) Same scheme than in (a) but there is an abnormal maturation of the oocyte and the female pronuclei is destroyed after division of the male pronuclei. (c) Maternal of NLRP7 mutation responsible for CHM or PMH. In this case the mole is biparental and rarely androgenic. (d) PHM, fertilization of a normal oocyte by two haploid spermatozoa or a diploid spermatozoon, $46, \mathrm{XY}$.

\section{Conclusion}

We can assess that histopathologic exam is very important in our context because of the high prevalence of HM. the lack of histopathological exam can lead to a high number of undiagnosed HM and a lack of early management of choriocarcinoma. We recommend accessibility for routine and systematic histopathological examination of all products of conception.

\section{Conflicts of Interest}

The authors declare no conflicts of interest regarding the publication of this paper.

\section{References}

[1] Heath, V., Chadwick, V., Cooke, I., Manek, S. and MacKenzie, I.Z. (2000) Should 
Tissue from Pregnancy Termination and Uterine Evacuation Routinely Be Examined Histologically? British Journal of Obstetrics and Gynaecology, 107, 727-730. https://doi.org/10.1111/j.1471-0528.2000.tb13332.x

[2] Grimes, D.A. (1984) Epidemiology of Gestational Trophoblastic Disease. American Journal of Obstetrics \& Gynecology, 150, 309-318.

https://doi.org/10.1016/S0002-9378(84)90370-3

[3] Slim, R., Coullin, P., Diatta, A.L., Chebaro, W., Courtin, D., Abdelhak, S. and Garcia, A. (2012) NLRP7 and the Genetics of Post-Molar Choriocarcinomas in Senegal. Molecular Human Reproduction, 18, 52-56. https://doi.org/10.1093/molehr/gar060

[4] Afoutou, J.M., Moreau, J.C., Couillin, Ph. and Correa, P. (1991) Physiopathologie des Trophoblastomes Benins. Bulletin de la Société médicale d'Afrique noire de langue française, 30, 165-174.

[5] Couillin, P., Afoutou, J.M., Faye, O., Ravisé, N., Correa, P. and Boué, A. (1985) Androgenetic Origin of African Complete Hydatidiform Moles Demonstrated by HLA Markers. Human Genetics, 71, 113-116.

[6] Sebire, N.J., Rees, H., Paradinas, F., Seckl, M. and Newlands, E. (2001) The Diagnostic Implications of Routine Ultrasound Examination in Histologically Confirmed Early Molar Pregnancies. Ultrasound in Obstetrics \& Gynecology, 18, 662-665.

[7] Savage, P.M., Sita-Lumsden, A., Dickson, S., Iyer, R., Everard, J., Coleman, R., Fisher, R.A., Short, D., Casalboni, S., Catalano, K., et al. (2013) The Relationship of Maternal Age to Molar Pregnancy Incidence, Risks for Chemotherapy and Subsequent Pregnancy Outcome. Journal of Obstetrics and Gynaecology, 33, 406-411. https://doi.org/10.1046/j.0960-7692.2001.00589.x

[8] Lazrak, I., Ihssane, H., Babahabib, M.A., Kouach, J., El Ochi, M.R., Moulay, Moussaoui, D. and Dehayni, M. (2014) Partial Invasive and Metastatic Hydatidiform Mole: Report of a Case. Pan African Medical Journal, 19, 175. https://doi.org/10.3109/01443615.2013.771159

[9] Seckl, M.J., Fisher, R.A., Salerno, G., Rees, H., Paradinas, F.J., Foskett, M. and Newlands, E.S. (2000) Choriocarcinoma and Partial Hydatidiform Moles. The Lancet, 356, 36-39. https://doi.org/10.11604/pamj.2014.19.175.5487

[10] Cisse, C.T., Lo, N., Moreau, J.C., Fall-Gaye, C., Mendez, V. and Diadhiou, F. (2002) Choriocarcinoma in Senegal: Epidemiology, Prognosis and Prevention. Gynécologie Obstétrique \& Fertilité, 30, 862-869. https://doi.org/10.1016/S0140-6736(00)02432-6

[11] Sebire, N.J. and Seckl, M.J. (2008) Gestational Trophoblastic Disease: Current Management of Hydatidiform Mole. British Medical Journal, 337, 453-458. https://doi.org/10.1016/S1297-9589(02)00456-3

[12] Pal, A.K., Ambulkar, P.S., Waghmare, J.E., Wankhede, V., Shende, M.R. and Tarnekar, A.M. (2018) Chromosomal Aberrations in Couples with Pregnancy Loss: A Retrospective Study. Reproductive Sciences, 11, 247-253. https://doi.org/10.1136/bmj.a1193

[13] Mulisya, O., Roberts, D.J., Sengupta, E.S, Agaba, E., Laffita, D., Tobias, T., Mpiima, D.P., Henry, L., Augustine, S., Abraham, M., Hillary, T. and Mugisha, J. (2018) Prevalence and Factors Associated with Hydatidiform Mole among Patients Undergoing Uterine Evacuation at Mbarara Regional Referral Hospital. Obstetrics and Gynecology International, 2018, Article ID: 9561413. https://doi.org/10.4103/jhrs.JHRS_124_17

[14] Ravindra, S., Prasad, S. and Suguna, B.V. (2016) Histomorphology of Fallopian Tubes in Ectopic Pregnancy. Archives of Medicine and Health Sciences, 4, 201-204. 
https://doi.org/10.1155/2018/9561413

[15] Skibsted, L., Sperling, L., Hansen, U. and Hertz, J. (1991) Salpingitis Isthmica Nodosa in Female Infertility and Tubal Diseases. Human Reproduction, 6, 828-831. https://doi.org/10.1093/oxfordjournals.humrep.a137436

[16] Altieri, A., Franceschi, S., Ferlay, J., Smith, J. and La Vecchia, C. (2003) Epidemiology and Etiology of Gestational Trophoblastic Diseases. The Lancet Oncology, 4, 670-678. https://doi.org/10.1016/S1470-2045(03)01245-2

[17] Faye, O., Moreau, J.C., Thiaw, O.T., Mattei, X. and Moreau, J.C. (1999) Étude ultrastructurale de la môle hydatiforme au Sénégal : Données préliminaires. Revue française de gynécologie et d'obstétrique, 95, 409-413.

[18] Jeffers, M.D., O’Dwyer, P., Curran, B., Leader, M. and Gillan, J.E. (1993) Partial Hydatidiform Mole: A Common but Underdiagnosed Condition. A 3-Year Retrospective Clinicopathological and DNA Flow Cytometric Analysis. International Journal of Gynecological Pathology, 12, 315-323.

[19] Genest, D.R. (2001) Partial Hydatidiform Mole: Clinicopathological Features, Differential Diagnosis, Ploidy and Molecular Studies, and Gold Standards for Diagnosis. International Journal of Gynecological Pathology, 20, 315-322. https://doi.org/10.1097/00004347-200110000-00001

[20] Moodley, M., Tunkyi, K. and Moodley, J. (2003) Gestational Trophoblastic Syndrome: An Audit of 112 Patients. A South African Experience. International Journal of $G y$ necologic Cancer, 13, 234-239. https://doi.org/10.1136/ijgc-00009577-200303000-00023

[21] Xue, W.C., Chan, K.Y., Feng, H.C., Chiu, P.M., Ngan, H.Y., Tsao, S.W. and Cheung, A.N. (2004) Promoter Hypermethylation of Multiple Genes in Hydatidiform Mole and Choriocarcinoma. The Journal of Molecular Diagnostics, 6, 326-334. https://doi.org/10.1016/S1525-1578(10)60528-4

[22] Gueye, M., Ndiaye-Gueye, M.D., Gueye, S.M.K. and Moreau, J.C. (2016) Fatal Cases of Gestational Trophoblastic Neoplasia in a National Trophoblastic Disease Reference Center in Dakar Senegal. International Journal of MCH and AIDS, 5, 32-38. https://doi.org/10.21106/ijma.90

[23] Poaty, H., Coullin, P., Leguern, E., Dessen, P., Valent, A., Afoutou, J.M., Peko, J.F., Candelier, J.J., Gombé-Mbalawa, C., Picard, J.Y. and Bernheim, A. (2012) Cytogenomic Studies of Hydatiform Moles and Gestational Choriocarcinoma. Bulletin du Cancer, 99, 827-843. https://doi.org/10.1684/bdc.2012.1621

[24] Poaty, H., Coullin, P., Peko, J.F., Dessen, P., Diatta, A.L., Valent, A., Leguern, E., Prévot, S., Gombé-Mbalawa, C., Candelier, J.J., Picard, J.Y. and Bernheim, A. (2012) Genome-Wide High-Resolution aCGH Analysis of Gestational Choriocarcinomas. PLoS ONE, 7, e29426. https://doi.org/10.1371/journal.pone.0029426

[25] May, J. and Stark, Z. (2015) Thomas Partial Hydatidiform Mole Following Intracytoplasmic Sperm Injection and the Transfer of a Cryopreserved-Thawed Blastocyst. Journal of Obstetrics and Gynaecology, 35, 320-321. https://doi.org/10.3109/01443615.2014.948397

[26] Paradinas, F.J. (1998) The Diagnosis and Prognosis of Molar Pregnancy: The Experience of the National Referral Centre in London. International Journal of Gynecology \& Obstetrics, 60, S57-S64. https://doi.org/10.1016/S0020-7292(98)80006-4

[27] Kim, K.R., Park, B.H., Hong, Y.O., Kwon, H.C. and Robboy, S.J. (2009) The Villous Stromal Constituents of Complete Hydatidiform Mole Differ Histologically in Very Early Pregnancy from the Normally Developing Placenta. The American Journal of Surgical Pathology, 33, 176-185. https://doi.org/10.1097/PAS.0b013e31817fada1 
[28] Madi, J.M., Braga, A.R, Paganella, M.P., Litvin, I.E. and Da Ros Wendland, E.M. (2016) Accuracy of p57 ${ }^{\text {KIP2 }}$ Compared with Genotyping for the Diagnosis of Complete Hydatidiform Mole: Protocol for a Systematic Review and Meta-Analysis. Systematic Reviews, 5, 169. https://doi.org/10.1186/s13643-016-0349-7

[29] Lewis, G.H., De Scipio, C. and Murphy, K.M. (2013) Characterization of Androgenetic/Biparental Mosaic/Chimeric Conceptions, Including Those with a Molar Component: Morphology, p57 Immunohistochemistry, Molecular Genotyping, and Risk of Persistent Gestational Trophoblastic Disease. International Journal of Gynecological Pathology, 32, 199-214. https://doi.org/10.1097/PGP.0b013e3182630d8c 